\title{
Desenvolvimento vegetativo e custo de produção de porta-enxertos de citros em recipientes para fins de subenxertia
}

\author{
Eduardo Augusto Girardi(1), Francisco de Assis Alves Mourão Filho( ${ }^{(1)}$ e Sônia Maria de Stefano Piedade ${ }^{(1)}$ \\ (1)Escola Superior de Agricultura Luiz de Queiroz, Av. Pádua Dias, 11, Caixa Postal 9, CEP 13418-900 Piracicaba, SP. \\ E-mail: eagirard@esalq.usp.br, famourao@esalq.usp.br, soniamsp@esalq.usp.br
}

\begin{abstract}
Resumo - O objetivo deste trabalho foi avaliar o desenvolvimento vegetativo e estimar o custo de produção de 11 porta-enxertos de citros para fins de subenxertia, em diferentes recipientes. Avaliaram-se limão 'Cravo' clone Limeira (Citrus limonia Osbeck); citrumelo 'Swingle' (Poncirus trifoliata (L.) Raf. x Citrus paradisi Macf.); tangerina 'Cleópatra' (Citrus reshni Hort. ex Tanaka); tangerina 'Sunki' (Citrus sunki Hort. ex Tanaka); limão 'Volkameriano' clone Catânia 2 (Citrus volkameriana Pasquale); laranja 'Caipira' clone DAC (Citrus sinensis L. Osbeck); limão 'Rugoso da África' clone Mazoe (Citrus jambhiri Lush.); Poncirus trifoliata 'Davis A'; tangerina 'Sun Shu Sha Kat' (Citrus sunki Hort. ex Tanaka); tangerina 'Sunki' clone 2506 ou Fruto Grande (Citrus sunki Hort. ex Tanaka) e Poncirus trifoliata 'Barnes'. Foram utilizados tubetes de $290 \mathrm{~mL}$, sacolas de 1,7 L, e portaenxertos transplantados de tubetes de $75 \mathrm{~mL}$ para sacolas de polietileno de 1,7 e 4,5 L. Porta-enxertos produzidos diretamente em sacolas de 1,7 L atingem ponto ideal de subenxertia em menor tempo, de 100 a 150 dias após a semeadura, e permitem a obtenção de plantas maiores e com sistema radicular adequado, porém com custo de produção superior ao sistema de produção em tubetes de $290 \mathrm{~mL}$.
\end{abstract}

Termos para indexação: Citrus spp., fruticultura, morte súbita dos citros, propagação, técnicas de enxertia.

\section{Vegetative development and production cost of citrus rootstocks in containers for inarching}

\begin{abstract}
The vegetative development and the estimation of the production cost of eleven citrus rootstocks for inarching were evaluated in different containers. 'Rangpur' lime cultivar Limeira (Citrus limonia Osbeck); 'Swingle' citrumelo (Poncirus trifoliata (L.) Raf. x Citrus paradisi Macf.); 'Cleópatra' mandarin (Citrus reshni Hort. ex Tanaka); 'Sunki' mandarin (Citrus sunki Hort. ex Tanaka); 'Volkamer' lemon cultivar Catânia 2 (Citrus volkameriana Pasquale); 'Caipira' sweet orange cultivar DAC (Citrus sinensis L. Osbeck); 'Rugoso da África' rough lemon cultivar Mazoe (Citrus jambhiri Lush.); Poncirus trifoliata cultivar Davis A; 'Sun Shu Sha Kat' mandarin (Citrus sunki Hort. ex Tanaka); 'Sunki' mandarin cultivar 2506 or Fruto Grande (Citrus sunki Hort. ex Tanaka) and Poncirus trifoliata cultivar Barnes were studied. Containers used were: $290 \mathrm{~mL}$ leaching tubes, $1.7 \mathrm{~L}$ polyethylene bags, and rootstocks transplanted from $75 \mathrm{~mL}$ leaching tubes to 1.7 and $4.5 \mathrm{~L}$ polyethylene bags. Rootstocks directly sowed in $1.7 \mathrm{~L}$ polyethylene bags reach optimal size for inarching in the shortest period, 100 to 150 days after sowing. They also lead to larger plants with satisfactory root system, however with a higher cost of production when compared to production system in $290 \mathrm{~mL}$ leaching tubes.
\end{abstract}

Index terms: Citrus spp., fruit crops, citrus sudden death disease, propagation, grafting.

\section{Introdução}

A subenxertia é uma técnica de multiplicação vegetativa que permite atribuir à copa novos portaenxertos, para substituir o original afetado por problemas fitossanitários ou problemas traumáticos, que causam deficiências no desenvolvimento das plantas (Müller et al., 2002). A subenxertia foi utilizada com sucesso na prevenção da tristeza-dos-citros (CTV) em porta- enxertos de laranja-azeda, afetados na Espanha e em Israel (Shaked et al., 1987; Moreno et al., 1994). O citrumelo 'Swingle' se mostrou um excelente portaenxerto para fins de subenxertia na prevenção da CTV, e quanto mais novos foram os subenxertos e as plantas a serem subenxertadas, mais rápida foi a recuperação, sem prejuízo algum à produção da copa (Shaked et al., 1987). No Japão, a subenxertia foi empregada para 
promover revigoramento e aumento da produção em pomeleiro (Nakajima et al., 1992).

Cerca de $80 \%$ do parque citrícola no Brasil está enxertado sobre o limão 'Cravo', porta-enxerto intolerante à morte súbita dos citros (MSC) (Pompeu Junior, 2005). A subenxertia vem sendo utilizada como técnica cultural de prevenção da MSC, em pomares nos quais ainda não se observa a doença ou na recuperação de plantas em estádios iniciais de manifestação de sintomas (Tersi, 2004). Essa técnica consiste no emprego de porta-enxertos tolerantes à MSC, como citrumelo 'Swingle' e tangerina 'Cleópatra', subenxertados em tecido da copa, a $35 \mathrm{~cm}$ do nível do solo. Para o uso do método do T-invertido, os porta-enxertos devem apresentar tecido maduro e diâmetro de cerca de 0,3 a $1 \mathrm{~cm}$ na altura da subenxertia. Utiliza-se de um a quatro subenxertos por árvore, conforme a idade da árvore, condições técnicas e grau de infestação da MSC do pomar (Tersi et al., 2003). Cerca de seis milhões de subenxertos já foram realizados até 2006 , e é a única forma de controle da doença atualmente, além de não acarretar diminuição na produção ou longevidade dos pomares subenxertados (Fundecitrus, 2006).

O objetivo deste trabalho foi avaliar o desenvolvimento vegetativo e estimar o custo de produção de 11 portaenxertos de citros, produzidos em diferentes recipientes em ambiente protegido, para fins de subenxertia.

\section{Material e Métodos}

O trabalho foi conduzido em estufa comercial telada para produção de mudas cítricas, no Município de Araras, SP, a $22^{\circ} 25^{\prime} 15^{\prime \prime} \mathrm{S}$ e $47^{\circ} 17^{\prime} 52^{\prime \prime} \mathrm{W}$. O clima da região é do tipo Cwa. Verificaram-se, no interior da estufa, temperaturas máximas e mínimas (médias) no verão e no inverno, respectivamente, de 40,5 e $18,6^{\circ} \mathrm{C}$ e 34,6 e $13,5^{\circ} \mathrm{C}$, e umidade relativa média no verão e no inverno, respectivamente, de 60 e $70 \%$, entre novembro de 2003 e setembro de 2004.

Foram avaliados 11 porta-enxertos, dos quais oito de importância comercial atual: limão 'Cravo' clone Limeira (Citrus limonia Osbeck); citrumelo 4475 ou 'Swingle' (Poncirus trifoliata x Citrus paradisi); tangerina 'Cleópatra' (Citrus reshni Hort. ex Tanaka); tangerina 'Sunki' (Citrus sunki Hort. ex Tanaka); limão 'Volkameriano' clone Catânia 2 (Citrus volkameriana Pasquale); laranja 'Caipira' clone DAC (Citrus sinensis L. Osbeck); limão 'Rugoso da África' clone Mazoe
(Citrus jambhiri Lush.) e Poncirus trifoliata 'Davis A'; e três com potencial para expansão de exploração na citricultura brasileira: tangerina 'Sun Shu Sha Kat' (Citrus sunki Hort. ex Tanaka), tangerina 'Sunki' clone 2506 ou Fruto Grande (Citrus sunki Hort. ex Tanaka) e Poncirus trifoliata 'Barnes'. Os portaenxertos comerciais, à exceção do limão 'Cravo' e do limão 'Volkameriano', não demonstram intolerância à MSC em pomares, e seu uso é recomendado para fins de subenxertia, pelo Fundo de Defesa da Citricultura (Fundecitrus, 2006).

As sementes dos porta-enxertos foram obtidas de frutos maduros, coletados no Banco de Germoplasma, do Centro APTA Citros Sylvio Moreira, e no campo de plantas-matrizes da SaniCitrus Mudas Cítricas, em junho de 2003. As sementes foram extraídas manualmente, submetidas a secagem à sombra por 24 horas e, posteriormente, embaladas em jornal, com aplicação de fungicida apropriado. As sementes foram mantidas em refrigerador a $5^{\circ} \mathrm{C}$ até a semeadura, em novembro de 2003, quando, então, se extraiu seu tegumento externo (testa), a fim de acelerar a emergência e, portanto, auxiliar na otimização da produção dos subenxertos (Girardi et al., 2007).

Foram avaliados três recipientes, com finalidade exclusiva para subenxertia: porta-enxertos semeados em tubetes de $290 \mathrm{~mL}$, em bancadas de arame suspenso; porta-enxertos semeados diretamente em sacolas de plástico de 1,7 L, sobre bancadas de concreto; porta-enxertos em tubetes convencionais de $75 \mathrm{~mL}$, posteriormente transplantados para sacolas de plástico de 1,7 L. Avaliou-se também a produção dos porta-enxertos em tubetes de $75 \mathrm{~mL}$, com posterior transplante para sacolas de 4,5 L, pois é o sistema convencionalmente empregado para fins de enxertia e formação das mudas no viveiro, que funcionou como padrão para cada porta-enxerto.

Todos os porta-enxertos foram submetidos aos tratos culturais e programa nutricional recomendados para produção de porta-enxertos aptos à enxertia em curto prazo (Carvalho et al., 2005). Foi semeada manualmente uma semente sem testa em cada recipiente. Nos tubetes de $75 \mathrm{~mL}$, utilizou-se o substrato comercial Plantmax Citrus, à base de casca de pinus e de baixa granulometria. Nos demais recipientes, utilizou-se substrato comercial Rendmax Citrus, à base de casca de pinus e de grânulos maiores. A razão da escolha foi o menor preço do último substrato, bem como sua melhor adaptação a recipientes de maior 
capacidade. As sementes foram recobertas por uma fina camada de Plantmax Citrus em todos os tratamentos.

Os porta-enxertos produzidos nos tubetes de $75 \mathrm{~mL}$ foram transplantados para as sacolas de plástico, em março de 2004, aproximadamente quatro meses após a semeadura, e o ensaio foi concluído em setembro de 2004

$\mathrm{O}$ delineamento experimental adotado foi o fatorial $11 \times 4$ (porta-enxerto x sistema de produção), perfazendo 44 tratamentos, em quatro blocos casualizados. A parcela experimental foi constituída de oito plantas, dispostas linearmente em bancadas ou em bandejas de tubetes. $\mathrm{Na}$ análise estatística dos dados referentes à emergência, utilizou-se esquema fatorial 11x3, já que a etapa de semeadura em tubetes foi a mesma, tanto para plantas transplantadas para sacolas de 1,7 L quanto para as transplantadas para sacolas de 4,5 L. Os dados foram submetidos à análise de variância, e as médias foram comparadas pelo teste de Tukey, a 5\% de probabilidade, tendo-se realizado a transformação do tipo arc sen $[(x+\alpha) / 100]^{0,5}$ para fins de análise estatística das variáveis percentuais.

Foram coletados os seguintes dados biométricos: porcentagem de emergência 56 dias após a semeadura; índice de velocidade de germinação (IVG), calculado conforme Nakagawa (1994); altura (cm) de plantas 240 dias após o plantio, medidos com trena; diâmetro (cm) do caule a $35 \mathrm{~cm}$ do colo da planta, medido com paquímetro digital 240 dias após plantio; massa (g) da matéria seca e fresca, de parte aérea e sistema radicular, 240 dias após o plantio (emprego de três plantas por parcela, com as medidas obtidas em balança digital, e a secagem realizada em estufa, por 72 horas a $64^{\circ} \mathrm{C}$ ); volume $(\mathrm{mL})$ de sistema radicular oito meses após a semeadura, medido por deslocamento de volume de água em proveta graduada; concentração de clorofila nas folhas (SPAD), medido com clorofilômetro Minolta SPAD-502, oito meses após a semeadura, em folhas maduras do terço superior da copa (Gil et al., 2002; Esposti et al., 2003). Ao final do experimento, foi realizada a comparação entre os custos de produção de cada sistema, com base nos trabalhos de Pozzan \& Kanashiro (2004).

\section{Resultados e Discussão}

A emergência foi mais veloz nos porta-enxertos semeados nos tubetes de $75 \mathrm{~mL}$ (Tabela 1). Nesse sistema (semeadura em tubetes de $75 \mathrm{~mL}$ ), verificouse que as sementes ficaram mais superficiais, enquanto nos outros dois sistemas (tubetes de $290 \mathrm{~mL}$ e sacolas de $1,7 \mathrm{~L}$ ), as sementes afundaram no substrato mais grosseiro. Esse fato pode explicar o atraso inicial na emergência. Contudo, de 21 até 56 dias após a semeadura, a porcentagem de emergência total, nos tubetes de $75 \mathrm{~mL}$, passou a ser menor que as demais. Como nos tubetes de $75 \mathrm{~mL}$ as sementes estavam mais superficiais, expostas recorrentemente ao sol direto, necessitavam de recobrimento constante com substrato. Este fato pode ter provocado a menor taxa de emergência, uma vez que as sementes de citros são bastante sensíveis à dessecação (Doijode, 2001).

Poncirus trifoliata 'Davis A', Poncirus trifoliata 'Barnes', citrumelo 'Swingle' e tangerina 'Sunki' foram os porta-enxertos com maior velocidade de germinação, independentemente do recipiente estudado (Tabela 1). Um

Tabela 1. Emergência medida 56 dias após a semeadura (DAS) e índice de velocidade de germinação, de 11 porta-enxertos de citros (Citrus spp.) semeados em tubetes de $75 \mathrm{~mL}(\mathrm{~A})$, tubetes de $290 \mathrm{~mL}(\mathrm{~B})$ e sacolas de $1,7 \mathrm{~L}(\mathrm{C})^{(1)}$.

\begin{tabular}{|c|c|c|c|c|c|c|c|c|}
\hline \multirow[t]{2}{*}{ Porta-enxerto } & \multicolumn{4}{|c|}{ Porcentagem de emergência 56 DAS } & \multicolumn{4}{|c|}{ Índice de velocidade de germinação } \\
\hline & $\mathrm{A}$ & $\mathrm{B}$ & $\mathrm{C}$ & Média & $\mathrm{A}$ & $\mathrm{B}$ & $\mathrm{C}$ & Média \\
\hline Limão 'Cravo' & $96,9 \mathrm{Bab}$ & $93,7 \mathrm{Ba}$ & $100,0 \mathrm{Aa}$ & $96,9 \mathrm{ab}$ & $1,32 \mathrm{Ac}$ & $1,17 \mathrm{Bde}$ & $1,33 \mathrm{Ab}$ & $1,28 \mathrm{c}$ \\
\hline Citrumelo 'Swingle' & $96,9 \mathrm{Bab}$ & $100,0 \mathrm{Aa}$ & $100,0 \mathrm{Aa}$ & $99,0 \mathrm{ab}$ & $1,86 \mathrm{Ab}$ & $1,78 \mathrm{ABa}$ & $1,76 \mathrm{Ba}$ & $1,80 \mathrm{a}$ \\
\hline Tangerina 'Cleópatra' & $100,0 \mathrm{Aa}$ & $96,9 \mathrm{Ba}$ & $100,0 \mathrm{Aa}$ & $99,0 \mathrm{ab}$ & $1,47 \mathrm{Ac}$ & $1,28 \mathrm{Cde}$ & $1,37 \mathrm{Bb}$ & $1,38 b$ \\
\hline Tangerina 'Sunki' & $100,0 \mathrm{Aa}$ & $100,0 \mathrm{Aa}$ & $100,0 \mathrm{Aa}$ & $100,0 \mathrm{a}$ & $1,98 \mathrm{Aab}$ & $1,76 \mathrm{Ba}$ & $1,74 \mathrm{Ba}$ & $1,83 \mathrm{a}$ \\
\hline Limão 'Volkameriano' & $78,1 \mathrm{Be}$ & $93,7 \mathrm{Aa}$ & $78,1 \mathrm{Bb}$ & $83,3 \mathrm{c}$ & $0,92 \mathrm{Ae}$ & $0,94 \mathrm{Ae}$ & $0,92 \mathrm{Ac}$ & $0,93 \mathrm{e}$ \\
\hline Laranja 'Caipira' & $93,7 \mathrm{Bbc}$ & $96,9 \mathrm{Aa}$ & $100,0 \mathrm{Aa}$ & $96,9 \mathrm{ab}$ & 1,13Ade & $1,09 \mathrm{Ae}$ & $1,12 \mathrm{Ac}$ & $1,11 \mathrm{~d}$ \\
\hline Limão 'Rugoso' & $92,2 \mathrm{Bbc}$ & $100,0 \mathrm{Aa}$ & $100,0 \mathrm{Aa}$ & $97,4 \mathrm{ab}$ & $1,36 \mathrm{Ac}$ & $1,42 \mathrm{Ac}$ & $1,42 \mathrm{Ab}$ & $1,40 \mathrm{~b}$ \\
\hline Trifoliata 'Davis $\mathrm{A}^{\prime}$ & $100,0 \mathrm{Aa}$ & $100,0 \mathrm{Aa}$ & $100,0 \mathrm{Aa}$ & $100,0 \mathrm{a}$ & $2,11 \mathrm{Aa}$ & $1,64 \mathrm{Bb}$ & $1,64 \mathrm{Ba}$ & $1,80 \mathrm{a}$ \\
\hline Trifoliata 'Barnes' & $98,4 \mathrm{Aab}$ & $100,0 \mathrm{Aa}$ & $100,0 \mathrm{Aa}$ & $99,5 \mathrm{ab}$ & $2,13 \mathrm{Aa}$ & $1,82 \mathrm{Ba}$ & $1,69 \mathrm{Ca}$ & $1,88 \mathrm{a}$ \\
\hline Tangerina 'Sun Shu Sha Kat' & $82,8 \mathrm{Bcd}$ & $100,0 \mathrm{Aa}$ & $100,0 \mathrm{Aa}$ & $94,3 b$ & $1,24 \mathrm{Bcd}$ & $1,37 \mathrm{Ac}$ & $1,37 \mathrm{Ab}$ & $1,33 \mathrm{bc}$ \\
\hline Tangerina 'Sunki' 2506 & $82,8 \mathrm{Bcd}$ & $100,0 \mathrm{Aa}$ & $100,0 \mathrm{Aa}$ & $94,2 b$ & $1,14 \mathrm{Bde}$ & $1,32 \mathrm{Acd}$ & $1,36 \mathrm{Ab}$ & $1,28 \mathrm{c}$ \\
\hline Média & $92,9 \mathrm{~B}$ & $98,3 \mathrm{~A}$ & $98,0 \mathrm{~A}$ & & $1,52 \mathrm{~A}$ & $1,42 \mathrm{~B}$ & $1,43 \mathrm{~B}$ & \\
\hline
\end{tabular}

${ }^{(1)}$ Médias seguidas por letras diferentes, maiúsculas nas linhas e minúsculas nas colunas, diferem entre si a 5\% de probabilidade, pelo teste de Tukey. 
mês após a semeadura, porém, todos os porta-enxertos já superavam $90 \%$ de emergência, com exceção do limão 'Volkameriano' (69,8\%). Mesmo na contagem final, 56 dias após a semeadura, esse porta-enxerto não superou 83,3\% de emergência (Tabela 1). Tangerina 'Sunki' e Poncirus trifoliata 'Davis A' foram os únicos porta-enxertos com $100 \%$ de emergência. O comportamento dos porta-enxertos, com relação à extração da testa, taxa de emergência e velocidade de germinação, é semelhante ao caracterizado em outros trabalhos (Radhamani et al., 1991; Soares Filho et al., 2002).

Plantas produzidas em sacolas de 1,7 $\mathrm{L}$ atingiram as maiores alturas 240 dias após a semeadura (Tabela 2). Até 90 dias após a semeadura, plantas semeadas em tubetes de $290 \mathrm{~mL}$ atingiram a segunda maior altura, mas, a partir de 120 dias após a semeadura, foram superadas pelas plantas transplantadas de tubetes de $75 \mathrm{~mL}$ para sacolas de 1,7 ou $4,5 \mathrm{~L}$. O transplante ocorreu entre 90 e 120 dias após a semeadura. Isto indica que houve proporcionalidade direta entre o volume de substrato e o crescimento dos porta-enxertos cítricos e, posteriormente, das mudas cítricas, conforme observado por Girardi et al. (2005). Após o transplante, os porta-enxertos voltaram a crescer de modo intenso, provavelmente em razão da maior disponibilidade de volume no container (Rezende et al., 1995).

Trifoliata 'Davis A', trifoliata 'Barnes' e citrumelo 'Swingle' apresentaram o maior vigor inicial, com maior desenvolvimento dos porta-enxertos até 150 dias após a semeadura. Entretanto, a partir desse estágio, trifoliata 'Davis A' apresentou crescimento menos intenso, de modo que 240 dias após a semeadura atingia apenas $49,20 \mathrm{~cm}$ de altura, em média, contra 93,35 cm do limão 'Rugoso', o maior porta-enxerto (Tabela 2). Trifoliata 'Barnes' superou 'Davis A' em $15 \mathrm{~cm}, 240$ dias após a semeadura (Tabela 2), e apresentou vigor mais acentuado nos últimos meses de avaliação do experimento. As trifoliatas e seus híbridos apresentam crescimento vigoroso em viveiros, porém, após a enxertia com variedades de outros gêneros da família Rutaceae, esse vigor, em geral, tende a desaparecer ou a se reduzir (Pompeu Junior, 2005). Como parte do experimento foi conduzida durante o outono e o inverno, as condições

Tabela 2. Altura total, diâmetro a $35 \mathrm{~cm}$ do colo e massa de matérias fresca e seca de sistema radicular, de 11 porta-enxertos de citros (Citrus spp.), 240 dias após semeadura em tubetes de $290 \mathrm{~mL}$ (A), sacolas de 1,7 L (B), tubetes de $75 \mathrm{~mL}$ seguida de transplante para sacolas de $1,7 \mathrm{~L}(\mathrm{C})$, e em tubetes de $75 \mathrm{~mL}$ seguida de transplante para sacolas de $4,5 \mathrm{~L}(\mathrm{D})^{(1)}$.

\begin{tabular}{|c|c|c|c|c|c|c|c|c|c|c|}
\hline \multirow[t]{2}{*}{ Porta-enxerto } & \multicolumn{10}{|c|}{ Recipientes } \\
\hline & $\mathrm{A}$ & $\mathrm{B}$ & $\mathrm{C}$ & $\mathrm{D}$ & Média & $\mathrm{A}$ & $\mathrm{B}$ & $\mathrm{C}$ & $\mathrm{D}$ & Média \\
\hline & \multicolumn{5}{|c|}{ 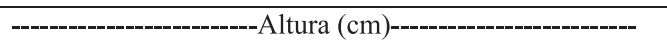 } & \multicolumn{5}{|c|}{ 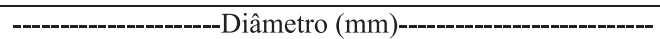 } \\
\hline Limão 'Cravo' & $43,8 \mathrm{Da}$ & $112,4 \mathrm{Ab}$ & $65,9 \mathrm{Cab}$ & $86,2 \mathrm{Bbc}$ & $77,1 \mathrm{~b}$ & $2,4 \mathrm{Ca}$ & $6,9 \mathrm{Ab}$ & $4,2 \mathrm{Bbc}$ & $4,9 \mathrm{Bbc}$ & $4,6 \mathrm{~b}$ \\
\hline Citrumelo 'Swingle' & $38,9 \mathrm{Ca}$ & 87,2 Acd & $50,6 \mathrm{Cbc}$ & $68,8 \mathrm{Bde}$ & $61,4 \mathrm{~cd}$ & $2,3 \mathrm{Ca}$ & $5,1 \mathrm{Ac}$ & $3,3 \mathrm{BCcd}$ & $4,0 \mathrm{Bcd}$ & $3,7 \mathrm{c}$ \\
\hline Tangerina 'Cleópatra' & $44,6 \mathrm{Ba}$ & 74,2Adef & $57,2 \mathrm{Bbc}$ & 72,4 Acd & $62,1 \mathrm{~cd}$ & $2,1 \mathrm{Ba}$ & $3,6 \mathrm{Ad}$ & $2,6 \mathrm{Ad}$ & 3,1Ade & $2,8 \mathrm{de}$ \\
\hline Tangerina 'Sunki' & $45,5 \mathrm{Ca}$ & $64,4 \mathrm{ABf}$ & $52,2 \mathrm{Bbc}$ & 68,8 Ade & $57,7 \mathrm{de}$ & $2,5 \mathrm{Ba}$ & 3,9Acd & 3,0Acd & $3,5 \mathrm{Acd}$ & $3,2 \mathrm{cde}$ \\
\hline Limão 'Volkameriano' & $41,0 \mathrm{Ca}$ & $116,0 \mathrm{Ab}$ & $78,7 \mathrm{Ba}$ & $89,8 \mathrm{Bb}$ & $81,4 \mathrm{~b}$ & $2,2 \mathrm{Ca}$ & $7,1 \mathrm{Ab}$ & $4,7 \mathrm{Bab}$ & $5,7 \mathrm{Bb}$ & $4,9 b$ \\
\hline Laranja 'Caipira' & $35,6 \mathrm{Aa}$ & $46,7 \mathrm{Ag}$ & $47,7 \mathrm{Ac}$ & $38,2 \mathrm{Af}$ & $42,0 \mathrm{~g}$ & $2,2 \mathrm{Ba}$ & $3,6 \mathrm{Ad}$ & $2,6 \mathrm{Ad}$ & $2,2 \mathrm{Be}$ & $2,6 \mathrm{e}$ \\
\hline Limão 'Rugoso' & $43,2 \mathrm{Da}$ & $144,8 \mathrm{Aa}$ & $78,1 \mathrm{Ca}$ & $107,3 \mathrm{Ba}$ & $93,3 \mathrm{a}$ & $2,3 \mathrm{Da}$ & $9,4 \mathrm{Aa}$ & $5,7 \mathrm{Ca}$ & $7,3 \mathrm{Ba}$ & $6,2 \mathrm{a}$ \\
\hline Trifoliata 'Davis $\mathrm{A}^{\prime}$ & $41,9 \mathrm{Ba}$ & 66,9Aef & $44,7 \mathrm{Bc}$ & $43,6 \mathrm{Bf}$ & $49,3 \mathrm{fg}$ & $1,6 \mathrm{Ca}$ & 3,9Acd & $2,6 \mathrm{Bd}$ & 2,9Abde & $2,8 \mathrm{de}$ \\
\hline Trifoliata 'Barnes' & $43,7 \mathrm{Ca}$ & $94,9 \mathrm{Ac}$ & $48,8 \mathrm{Cc}$ & $78,2 \mathrm{Bbc}$ & $66,4 \mathrm{c}$ & $2,4 \mathrm{Ca}$ & 4,4Acd & $2,9 \mathrm{BCd}$ & $3,7 \mathrm{ABcd}$ & $3,4 \mathrm{~cd}$ \\
\hline Tangerina 'Sun Shu Sha Kat' & $34,7 \mathrm{Ba}$ & $60,2 \mathrm{Afg}$ & $53,1 \mathrm{Abc}$ & $61,6 \mathrm{Ae}$ & $52,4 \mathrm{ef}$ & $2,0 \mathrm{Ca}$ & $3,5 \mathrm{Ad}$ & $2,8 \mathrm{BCd}$ & $3,4 \mathrm{ABde}$ & $2,9 \mathrm{de}$ \\
\hline Tangerina 'Sunki' 2506 & $47,7 \mathrm{Ca}$ & $79,2 \mathrm{Acd}$ & $61,2 \mathrm{Bbc}$ & $82,6 \mathrm{Abc}$ & $67,7 \mathrm{c}$ & $2,4 \mathrm{Ba}$ & 4,3Acd & $2,4 \mathrm{Bd}$ & $2,8 \mathrm{Bde}$ & 2,9de \\
\hline \multirow[t]{2}{*}{ Média } & $41,9 \mathrm{D}$ & $86,1 \mathrm{~A}$ & $58,0 \mathrm{C}$ & $72,5 \mathrm{~B}$ & & $2,2 \mathrm{D}$ & $5,1 \mathrm{~A}$ & $3,4 \mathrm{C}$ & $4,0 \mathrm{~B}$ & \\
\hline & \multicolumn{5}{|c|}{-----Massa de matéria fresca de sistema radicular (g)----- } & \multicolumn{5}{|c|}{------Massa de matéria seca de sistema radicular (g)------ } \\
\hline Limão 'Cravo' & $11,9 \mathrm{Da}$ & $60,4 \mathrm{Bab}$ & $32,6 \mathrm{Cab}$ & $77,3 \mathrm{Ab}$ & $45,6 \mathrm{~b}$ & $5,0 \mathrm{Ca}$ & $24,5 \mathrm{Aab}$ & $13,0 \mathrm{Bab}$ & $25,7 \mathrm{Aab}$ & $17,1 \mathrm{ab}$ \\
\hline Citrumelo 'Swingle' & $12,4 \mathrm{Ca}$ & $42,8 \mathrm{Abcd}$ & $26,4 \mathrm{Babc}$ & $40,9 \mathrm{Abcd}$ & $30,6 \mathrm{~cd}$ & $4,9 \mathrm{Ba}$ & $16,00 \mathrm{Aab}$ & $8,8 \mathrm{Aab}$ & $13,5 \mathrm{Abc}$ & $10,8 b c$ \\
\hline Tangerina 'Cleópatra' & $7,2 \mathrm{Ba}$ & $21,0 \mathrm{Ae}$ & $12,8 \mathrm{Acd}$ & $17,2 \mathrm{Ae}$ & $14,6 \mathrm{e}$ & $2,5 \mathrm{Ba}$ & $10,8 \mathrm{Ab}$ & $12,9 \mathrm{Aab}$ & $5,8 \mathrm{Bc}$ & $8,0 \mathrm{bc}$ \\
\hline Tangerina 'Sunki' & $11,1 \mathrm{Aa}$ & 24,8 Acde & $14,1 \mathrm{Abcd}$ & $21,0 \mathrm{Ae}$ & $17,7 \mathrm{e}$ & $4,2 \mathrm{Ba}$ & $7,6 \mathrm{Ab}$ & $3,5 \mathrm{Bb}$ & $6,1 \mathrm{Ac}$ & $5,3 c$ \\
\hline Limão 'Volkameriano' & $12,8 \mathrm{Ca}$ & $43,2 \mathrm{Abc}$ & $29,1 \mathrm{Babc}$ & $46,3 \mathrm{Ac}$ & $32,9 \mathrm{c}$ & $5,7 \mathrm{Ba}$ & $15,6 \mathrm{Aab}$ & 9,7Aab & $15,1 \mathrm{Abc}$ & $11,5 \mathrm{bc}$ \\
\hline Laranja 'Caipira' & $11,3 \mathrm{Aa}$ & 23,3Ade & 11,6 Acd & $14,1 \mathrm{Ae}$ & $15,1 \mathrm{e}$ & $4,2 \mathrm{Ba}$ & $7,4 \mathrm{Ab}$ & $3,2 \mathrm{Bb}$ & $3,8 \mathrm{Bc}$ & $4,6 \mathrm{c}$ \\
\hline Limão 'Rugoso' & $15,7 \mathrm{Da}$ & $80,1 \mathrm{Ba}$ & $44,9 \mathrm{Ca}$ & $115,7 \mathrm{Aa}$ & $64,1 \mathrm{a}$ & $7,4 \mathrm{Ca}$ & $32,4 \mathrm{Aa}$ & $16,9 \mathrm{Ba}$ & $39,5 \mathrm{Aa}$ & $24,1 \mathrm{a}$ \\
\hline Trifoliata 'Davis A' & $10,8 \mathrm{Ba}$ & 31,6 Acde & $7,2 \mathrm{Bd}$ & 33,7Acde & $20,8 \mathrm{de}$ & $3,8 \mathrm{Aa}$ & $9,9 \mathrm{Ab}$ & $10,0 \mathrm{Ab}$ & $12,7 \mathrm{Abc}$ & $7,1 \mathrm{c}$ \\
\hline Trifoliata 'Barnes' & $12,5 \mathrm{Ba}$ & 35,7 Acde & $14,1 \mathrm{Bbcd}$ & 32,9Acde & $23,7 \mathrm{cde}$ & $4,8 \mathrm{Ba}$ & $13,4 \mathrm{Aab}$ & $5,0 \mathrm{Bb}$ & $9,7 \mathrm{ABbc}$ & $8,2 \mathrm{bc}$ \\
\hline Tangerina 'Sun Shu Sha Kat' & $11,5 \mathrm{Aa}$ & $20,9 \mathrm{Ae}$ & $13,8 \mathrm{Abcd}$ & 25,9 Ade & $18,0 \mathrm{e}$ & $4,4 \mathrm{ba}$ & $6,2 \mathrm{Ab}$ & $3,8 \mathrm{Bb}$ & $8,3 \mathrm{Abc}$ & $5,7 \mathrm{c}$ \\
\hline Tangerina 'Sunki' 2506 & $7,9 \mathrm{Ba}$ & $20,1 \mathrm{Abe}$ & $12,5 \mathrm{Abcd}$ & 28,1 Acde & $17,1 \mathrm{e}$ & $2,9 \mathrm{ba}$ & $6,5 \mathrm{Ab}$ & $3,6 \mathrm{Bb}$ & $8,6 \mathrm{Abc}$ & $5,4 \mathrm{c}$ \\
\hline Média & $11,4 \mathrm{C}$ & $36,7 \mathrm{~A}$ & 19,9B & $41,2 \mathrm{~A}$ & & $4,5 \mathrm{~B}$ & $13,7 \mathrm{~A}$ & $6,9 \mathrm{~B}$ & $13,5 \mathrm{~A}$ & \\
\hline
\end{tabular}

${ }^{(1)}$ Médias seguidas por letras diferentes, maiúsculas nas linhas e minúsculas nas colunas, diferem entre si a 5\% de probabilidade, pelo teste de Tukey. 
climáticas também podem ter influenciado o comportamento dos clones de Poncirus trifoliata, classificada como uma espécie decídua, embora não se tenha observado queda de folhas durante o ensaio (Spiegel-Roy \& Goldschmidt, 1996).

A laranja 'Caipira' e a tangerina 'Sun Shu Sha Kat' apresentaram menores alturas, enquanto os portaenxertos mais vigorosos foram, em ordem decrescente, os limões 'Rugoso', 'Volkameriano' e 'Cravo' (Tabela 2). A tangerina 'Sunki' Fruto Grande apresentou excelente crescimento, superior ao da tangerina 'Sunki' comum e da tangerina 'Sun Shu Sha Kat', 240 dias após a semeadura (Tabela 2). Quando foi realizada a extração de sementes dos frutos, verificou-se também que a tangerina 'Sunki' Fruto Grande apresentava, em média, 15 sementes por fruto, enquanto a tangerina 'Sunki' comum alcançou média próxima a duas sementes por fruto.

No sistema de semeadura em tubetes de $290 \mathrm{~mL}$, todos os porta-enxertos se equivaleram em altura, 240 dias após a semeadura, e o mesmo fato ocorreu para as demais variáveis avaliadas (Tabelas 2 e 3 ). $\mathrm{O}$ menor volume do recipiente, provavelmente, limita os porta-enxertos até um máximo crescimento possível de ser atingido nessa circunstância, a partir do qual há pouco desenvolvimento, independentemente da espécie ou variedade (Nesmith \& Duval, 1997). Oito meses após a semeadura, observou-se que plantas produzidas em sacolas de $1,7 \mathrm{~L}$ atingiram maior diâmetro a $35 \mathrm{~cm}$ do colo, seguidas de porta-enxertos transplantados para sacolas de 4,5 L, porta-enxertos transplantados para sacolas de 1,7 L e, finalmente, porta-enxertos semeados em tubetes de $290 \mathrm{~mL}$ (Tabela 2). Novamente, o limão 'Rugoso' apresentou o maior diâmetro, seguido do limão 'Volkameriano', limão 'Cravo' e citrumelo 'Swingle'. A laranja 'Caipira' e as tangerinas apresentaram os menores diâmetros.

À exceção do limão 'Rugoso', com 6,2 mm, nenhum outro porta-enxerto apresentou diâmetro médio, em todos os tratamentos, maior que $5 \mathrm{~mm}$, medida considerada ideal para fins de subenxertia no Brasil (Tersi et al., 2003). Na realidade, tem se observado o sucesso do uso comercial de subenxertos bem menores do que essa recomendação, muitas vezes com plantas de apenas dois a três meses, cultivadas em tubetes de $75 \mathrm{~mL}$; ou se

Tabela 3. Massa de matérias fresca e seca de parte aérea, concentração de clorofila foliar e volume de sistema radicular, de 11 porta-enxertos de citros (Citrus spp.), 240 dias após semeadura em tubetes de $290 \mathrm{~mL}$ (A), sacolas de 1,7 L (B), tubetes de $75 \mathrm{~mL}$ seguida de transplante para sacolas de $1,7 \mathrm{~L}(\mathrm{C})$, e em tubetes de $75 \mathrm{~mL}$ seguida de transplante para sacolas de 4,5 L (D) ${ }^{(1)}$.

\begin{tabular}{|c|c|c|c|c|c|c|c|c|c|c|}
\hline \multirow[t]{2}{*}{ Porta-enxerto } & \multicolumn{10}{|c|}{ Recipientes } \\
\hline & $\mathrm{A}$ & $\mathrm{B}$ & $\mathrm{C}$ & $\mathrm{D}$ & Média & $\mathrm{A}$ & $\mathrm{B}$ & $\mathrm{C}$ & $\mathrm{D}$ & Média \\
\hline & \multicolumn{5}{|c|}{------Massa de matéria fresca da parte aérea (g)--------- } & \multicolumn{5}{|c|}{------ Massa de matéria seca da parte aérea (g) --------- } \\
\hline Limão 'Cravo' & $12,8 \mathrm{Ca}$ & $87,3 \mathrm{Ab}$ & $38,3 \mathrm{Bab}$ & $54,9 \mathrm{Bb}$ & $48,3 \mathrm{~b}$ & $5,4 \mathrm{Ca}$ & $35,9 \mathrm{Ab}$ & $16,3 \mathrm{Bab}$ & $22,4 \mathrm{Bab}$ & $20,0 \mathrm{~b}$ \\
\hline Citrumelo 'Swingle' & $10,2 \mathrm{Ca}$ & $48,1 \mathrm{Ac}$ & $25,1 \mathrm{Bab}$ & $30,0 \mathrm{ABbc}$ & $28,4 \mathrm{c}$ & $4,3 \mathrm{Ba}$ & $20,7 \mathrm{Ac}$ & 7,9Bab & $11,2 \mathrm{ABbc}$ & $11,0 \mathrm{c}$ \\
\hline Tangerina 'Cleópatra' & $12,0 \mathrm{Ba}$ & $37,3 \mathrm{Ac}$ & $17,3 \mathrm{ABb}$ & $28,7 \mathrm{Abc}$ & $23,8 \mathrm{~cd}$ & $4,2 \mathrm{Ba}$ & $13,1 \mathrm{Ac}$ & $5,9 \mathrm{Bb}$ & $10,8 \mathrm{Abc}$ & $8,5 \mathrm{c}$ \\
\hline Tangerina 'Sunki' & $14,3 \mathrm{Ba}$ & $38,6 \mathrm{Ac}$ & $20,3 \mathrm{ABb}$ & $27,2 \mathrm{ABbc}$ & $25,1 \mathrm{~cd}$ & $6,0 \mathrm{Ba}$ & $14,0 \mathrm{Ac}$ & $7,6 \mathrm{Bb}$ & $10,0 \mathrm{Abc}$ & $9,4 \mathrm{c}$ \\
\hline Limão 'Volkameriano' & $13,0 \mathrm{Ca}$ & 99,7Aab & $41,4 \mathrm{Bab}$ & $53,2 \mathrm{Bb}$ & $51,8 \mathrm{~b}$ & $5,4 \mathrm{Ca}$ & $38,0 \mathrm{Ab}$ & $15,8 \mathrm{Bab}$ & $20,8 \mathrm{Bab}$ & $20,0 \mathrm{~b}$ \\
\hline Laranja 'Caipira' & $10,9 \mathrm{Ba}$ & $28,6 \mathrm{Ac}$ & $18,4 \mathrm{ABb}$ & $18,2 \mathrm{ABc}$ & $19,0 \mathrm{~cd}$ & $4,4 \mathrm{Ba}$ & $10,2 \mathrm{Ac}$ & $6,1 \mathrm{ABb}$ & $4,9 \mathrm{Bc}$ & $6,4 c$ \\
\hline Limão 'Rugoso' & $24,9 \mathrm{Da}$ & $122,4 \mathrm{Aa}$ & $51,6 \mathrm{Ca}$ & $83,7 \mathrm{Ba}$ & $70,6 a$ & $5,6 \mathrm{Da}$ & $63,5 \mathrm{Aa}$ & $20,5 \mathrm{Ca}$ & $33,6 \mathrm{Ba}$ & $30,8 \mathrm{a}$ \\
\hline Trifoliata 'Davis $\mathrm{A}^{\prime}$ & $4,8 \mathrm{Ba}$ & $25,6 \mathrm{Ac}$ & $18,2 \mathrm{Ab}$ & $7,4 \mathrm{Bc}$ & $14,0 \mathrm{~d}$ & $4,0 \mathrm{Ba}$ & $11,6 \mathrm{Ac}$ & $5,4 \mathrm{Bb}$ & $6,0 \mathrm{Bc}$ & $6,2 \mathrm{c}$ \\
\hline Trifoliata 'Barnes' & $10,9 \mathrm{Ba}$ & $28,9 \mathrm{Ac}$ & $16,8 \mathrm{ABb}$ & $28,3 \mathrm{Abc}$ & $21,2 \mathrm{~cd}$ & $4,2 \mathrm{Ba}$ & $17,2 \mathrm{Ac}$ & $6,00 \mathrm{Bb}$ & $10,7 \mathrm{ABbc}$ & $9,5 \mathrm{c}$ \\
\hline Tangerina 'Sun Shu Sha Kat' & $9,6 \mathrm{Ba}$ & $29,7 \mathrm{Ac}$ & $16,1 \mathrm{Ab}$ & $19,3 \mathrm{Ac}$ & $18,7 \mathrm{~cd}$ & $3,6 \mathrm{Ba}$ & $10,6 \mathrm{Ac}$ & $5,7 \mathrm{Bb}$ & $6,5 \mathrm{Bc}$ & $6,6 \mathrm{c}$ \\
\hline Tangerina 'Sunki' 2506 & $12,0 \mathrm{Ba}$ & $37,9 \mathrm{Ac}$ & $20,2 \mathrm{ABb}$ & $32,8 \mathrm{Abc}$ & $25,7 \mathrm{~cd}$ & $4,5 \mathrm{Ba}$ & $13,3 \mathrm{Ac}$ & $7,6 \mathrm{Bb}$ & $12,5 \mathrm{Abc}$ & $9,5 \mathrm{c}$ \\
\hline \multirow[t]{2}{*}{ Média } & $12,3 \mathrm{D}$ & $53,1 \mathrm{~A}$ & $25,8 \mathrm{C}$ & 34,9B & & $4,5 \mathrm{D}$ & $22,6 \mathrm{~A}$ & $9,5 \mathrm{C}$ & $13,6 \mathrm{~B}$ & \\
\hline & \multicolumn{10}{|c|}{-----Concentração de clorofila nas folhas (SPAD) ${ }^{(2)}$----- } \\
\hline Limão 'Cravo' & 55,2 & 64,0 & 61,1 & 65,1 & $61,3 \mathrm{def}$ & $15,0 \mathrm{Ba}$ & $70,0 \mathrm{Aab}$ & $70,0 \mathrm{Aa}$ & $85,0 \mathrm{Ab}$ & $61,2 \mathrm{ab}$ \\
\hline Citrumelo 'Swingle' & 69,8 & 66,5 & 64,2 & 66,9 & $66,9 \mathrm{bcd}$ & $15,0 \mathrm{Ba}$ & $35,0 \mathrm{Bb}$ & $35,0 \mathrm{Bb}$ & 60,0 Acd & $30,0 \mathrm{c}$ \\
\hline Tangerina 'Cleópatra' & 62,0 & 61,9 & 57,9 & 54,7 & 59,1 def & $10,0 \mathrm{Ba}$ & $15,0 \mathrm{Bb}$ & $15,0 \mathrm{Bb}$ & 45,0Ade & $23,7 \mathrm{c}$ \\
\hline Tangerina 'Sunki' & 50,8 & 63,6 & 53,5 & 67,4 & $58,8 \mathrm{ef}$ & $12,5 \mathrm{Ba}$ & $25,0 \mathrm{Bb}$ & $25,0 \mathrm{Bb}$ & 45,0 Acd & $31,2 \mathrm{c}$ \\
\hline Limão 'Volkameriano' & 53,3 & 57,2 & 55,0 & 58,3 & $56,0 \mathrm{f}$ & $10,0 \mathrm{Ba}$ & $65,0 \mathrm{Aab}$ & $65,0 \mathrm{Aab}$ & $65,0 \mathrm{Abc}$ & $51,6 \mathrm{~b}$ \\
\hline Laranja 'Caipira' & 76,5 & 70,3 & 70,7 & 74,4 & $73,0 \mathrm{ab}$ & $10,0 \mathrm{Aa}$ & $30,0 \mathrm{Ab}$ & $30,0 \mathrm{Ab}$ & $30,0 \mathrm{Ae}$ & $20,0 \mathrm{c}$ \\
\hline Limão 'Rugoso' & 53,4 & 60,3 & 59,5 & 59,3 & $58,1 \mathrm{ef}$ & $15,0 \mathrm{Ca}$ & $85,0 \mathrm{Ba}$ & $85,0 \mathrm{Ba}$ & $100,0 \mathrm{Aa}$ & $69,4 \mathrm{a}$ \\
\hline Trifoliata 'Davis A' & 84,6 & 80,4 & 70,5 & 83,2 & $79,6 \mathrm{a}$ & $7,5 \mathrm{Aa}$ & $25,0 \mathrm{Ab}$ & $25,0 \mathrm{Ab}$ & $25,0 \mathrm{Ae}$ & $20,3 \mathrm{c}$ \\
\hline Trifoliata 'Barnes' & 74,4 & 75,0 & 75,0 & 73,7 & $72,0 \mathrm{abc}$ & $13,5 \mathrm{Ba}$ & $35,0 \mathrm{Ab}$ & $35,0 \mathrm{Ab}$ & 45,0 Acde & $29,5 \mathrm{c}$ \\
\hline Tangerina 'Sun Shu Sha Kat' & 61,9 & 64,8 & 60,7 & 66,3 & $63,4 \mathrm{def}$ & $10,0 \mathrm{Ba}$ & $35,0 \mathrm{Ab}$ & $35,0 \mathrm{Ab}$ & 40,0 Ade & $28,0 \mathrm{c}$ \\
\hline Tangerina 'Sunki' 2506 & 57,7 & 65,9 & 64,4 & 69,1 & 64,3 cde & $10,0 \mathrm{Ba}$ & $30,0 \mathrm{Ab}$ & $30,0 \mathrm{Ab}$ & 40,0 Acde & $30,6 \mathrm{c}$ \\
\hline Média & $62,0 \mathrm{~B}$ & $66,4 \mathrm{~A}$ & $63,6 \mathrm{AB}$ & $67,1 \mathrm{~A}$ & & $11,8 \mathrm{C}$ & $38,9 \mathrm{~B}$ & $38,9 \mathrm{~B}$ & $54,3 \mathrm{~A}$ & \\
\hline
\end{tabular}

${ }^{(1)}$ Médias seguidas por letras diferentes, maiúsculas nas linhas e minúsculas nas colunas, diferem entre si a $5 \%$ de probabilidade, pelo teste de Tukey.

(2)SPAD: índice absoluto "Soil Plant Analysis Development", que avalia quantitativamente a intensidade da cor verde da folha (Gil et al., 2002). 
tem realizado a subenxertia em mudas ainda no viveiro (Setin, 2005).

O padrão de subenxerto varia conforme a situação específica no campo, e quando a planta a se subenxertar for velha ou doente, deve-se usar maior número de subenxertos ou subenxertos mais vigorosos. A altura de $35 \mathrm{~cm}$ que permite a subenxertia acima do ponto de inserção da copa no porta-enxerto que se deseja substituir é o principal parâmetro usado no momento para se considerar a operação de subenxertia.

Observa-se que todas as plantas produzidas no experimento estariam aptas à subenxertia, e a maioria atingiu essa altura de 120 a 180 dias após a semeadura. Entretanto, porta-enxertos semeados diretamente em sacolas de 1,7 L foram os primeiros a atingir $35 \mathrm{~cm}$ de altura, como a trifoliata 'Davis A', aos 90 dias após a semeadura, e a trifoliata 'Barnes', o limão 'Cravo', o citrumelo 'Swingle' e o limão 'Rugoso' 30 dias depois. As tangerinas 'Sunki' e 'Cleópatra' só atingiram $35 \mathrm{~cm}$ de altura, em sacolas de 1,7 L, após 150 dias da semeadura. O transplante para sacolas de 4,5 $\mathrm{L}$ acelerou o crescimento das plantas, mas não é apropriado para fins de subenxertia em razão do seu alto custo e dificuldades operacionais de plantio em campo, o que sugere que o sistema de semear diretamente em sacolas de 1,7 L é o que permite a obtenção mais rápida da maioria dos portaenxertos em condições mais apropriadas para subenxertia no campo.

$\mathrm{O}$ crescimento dos subenxertos foi proporcional ao volume do recipiente, o que resultou em maiores massas de matérias fresca e seca de sistema radicular nos recipientes maiores, 240 dias após a semeadura (Tabela 2). Essas variáveis foram similares para todos os subenxertos produzidos em tubetes de $290 \mathrm{~mL}$. Tangerinas, trifoliatas e laranja 'Caipira' apresentaram massas de matéria seca equivalentes, contudo apenas tangerinas e laranja 'Caipira' atingiram os menores valores de massa de matéria fresca de sistema radicular. Os limões 'Rugoso' e 'Cravo' atingiram as maiores massas de matérias fresca e seca de sistema radicular. Essas observações condizem com trabalhos que descrevem a morfologia e anatomia do sistema radicular de porta-enxertos cítricos, em viveiros de campo e estufa na Flórida (Castle \& Youtsey, 1977; Castle, 1987). As mesmas considerações feitas para massas de matérias frescas e secas de sistema radicular são válidas para a parte aérea, com evidente superioridade dos três limões avaliados, e o limão 'Rugoso' foi o mais vigoroso de todos (Tabela 3).
Como existe correlação entre intensidade de coloração do tom verde do limbo foliar e concentração de clorofila nas folhas, a leitura do clorofilômetro, em termos do índice SPAD, pode ser utilizada como indicativo do estado nutricional da planta, em especial no que se refere à concentração de nitrogênio, por ser elemento integrante da molécula de clorofila (Esposti et al., 2003; Girardi \& Mourão Filho, 2004). Subenxertos produzidos diretamente em sacolas de 1,7 L ou transplantados de tubetes de $75 \mathrm{~mL}$ para sacolas de 4,5 L apresentaram maior concentração de clorofila nas folhas, em relação aos subenxertos produzidos em tubetes de $290 \mathrm{~mL}, 240$ dias após semeadura (Tabela 3). A capacidade do recipiente está diretamente vinculada ao desenvolvimento vegetativo e nutrição adequados de mudas cítricas (Rezende et al., 1995). O tubete de $290 \mathrm{~mL}$ limitou o espaço físico e a disponibilidade de nutrientes para as plantas e reduziu seu porte. Constatou-se início de deficiência nutricional, a partir de 180 dias após a semeadura, manifestada pelo amarelecimento das folhas.

Os subenxertos que atingiram as maiores concentrações de clorofila nas folhas foram trifoliata 'Davis A', laranja 'Caipira' e trifoliata 'Barnes', seguidos pelo citrumelo 'Swingle' em situação intermediária (Tabela 3). As tangerinas e os limões tiveram concentrações inferiores, em que os limões 'Volkameriano' e 'Rugoso' apresentaram as menores concentrações. Os limões e as tangerinas apresentaram, em geral, maior crescimento vegetativo do que $P$. trifoliata e laranja 'Caipira', este último foi o portaenxerto menos vigoroso. Possivelmente, as diferenças entre concentração de clorofila foliar sejam atribuídas a características genéticas inerentes a cada porta-enxerto, sob determinada condição do ambiente (Stoffella et al., 1995; Pestana et al., 2005).

O volume do sistema radicular foi diretamente proporcional ao volume do recipiente utilizado (Tabela 3). Assim, sacolas de 4,5 L permitiram sistema radicular mais volumoso, seguidas por sacolas de 1,7 L e por fim tubetes de $290 \mathrm{~mL}$. O transplante ou semeadura direta em sacolas de 1,7 L não determinaram diferenças no volume do sistema radicular. As espécies de limões atingiram o maior volume radicular, e o limão 'Rugoso' foi o que teve sistema radicular mais volumoso; no outro extremo se situaram as tangerinas, as trifoliatas e a laranja 'Caipira'. Independentemente do porta-enxerto, não houve diferença quanto ao volume de sistema radicular de plantas produzidas em tubetes de $290 \mathrm{~mL}$ (Tabela 3). Isto ocorreu porque o pequeno volume do tubete restringiu o sistema radicular de todas as 
espécies, além de o orifício de drenagem provocar poda aérea de radicelas que vieram a se desenvolver. A capacidade do recipiente, por ser diretamente proporcional à disponibilidade de recursos como água e nutrientes à planta, bem como acomodação do sistema radicular, é um fator decisivo para determinar a velocidade de crescimento do porta-enxerto e da muda, e indicar a viabilidade técnico-econômica do empreendimento (Girardi et al., 2005). O volume do recipiente pode influenciar, ainda, o desempenho de mudas frutíferas, hortícolas e florestais, após o transplante em campo (Nesmith \& Duval, 1997).

Somente em sacolas de 4,5 L, foi possível verificar que os porta-enxertos se agruparam em classes de volume de sistema radicular, em ordem decrescente: limão 'Rugoso', limão 'Volkameriano', limão 'Cravo', citrumelo 'Swingle' e as tangerinas, a trifoliata 'Davis A' e a laranja 'Caipira'. Assim, evidencia-se o hábito de crescimento de sistema radicular dessas espécies cítricas (Castle, 1978). Com maior disponibilidade de espaço, os limões continuaram a apresentar crescimento de sistema radicular de forma rápida, intensa e vigorosa. As demais espécies, mesmo com mais espaço disponível, ainda não haviam saturado o substrato com radicelas, 240 dias após a semeadura, pois têm crescimento mais lento. Este é um indicativo de que o ponto de transplante de limões para o campo pode ser anterior ao das demais espécies, inclusive para se evitarem problemas como enovelamento de raízes ou má formação da muda (Castle, 1987).

Os porta-enxertos podem ser, pois, divididos em três grupos decrescentes, quanto a seu desenvolvimento: limões, em que o limão 'Rugoso' clone Mazoe é o mais vigoroso; tangerinas e citrumelo 'Swingle', em situação intermediária; e, finalmente, P. trifoliata e laranja 'Caipira' DAC, esta última com menor desenvolvimento entre todos os porta-enxertos. É possível se estabelecerem expectativas quanto à formação das mudas e subenxertos, em ambiente protegido, independentemente do volume do recipiente, com esses três grupos de porta-enxertos. Destaca-se, também, a morfologia do sistema radicular das plantas semeadas diretamente em sacolas de 1,7 L, que apresentaram raiz pivotante definida e de comprimento correspondente à altura da sacola, ao contrário das plantas transplantadas, que apresentaram bifurcação do sistema radicular, no ponto de poda aérea do tubete, a cerca de $12 \mathrm{~cm}$ abaixo do colo. Todas as plantas apresentaram grande quantidade de raízes secundárias e radicelas, independentemente do recipiente empregado.
A estimação do custo de produção, realizada por Pozzan \& Kanashiro (2004), considera a formação da muda cítrica em ciclo de produção de nove meses, em recipientes de 5,38 L, com descarte de $5 \%$ do total de mudas produzidas. Neste experimento, o sistema de produção em tubetes de $290 \mathrm{~mL}$ foi o mais barato, com cerca de $\mathrm{R} \$ 0,22$ por porta-enxerto. Contudo, deve-se considerar o padrão inferior de desenvolvimento das plantas obtidas, e sua possível influência sobre o desenvolvimento pós-subenxertia em campo. Mudas cítricas convencionais, subenxertos diretamente semeados em sacolas de $1,7 \mathrm{~L}$, e subenxertos transplantados de tubetes para sacolas de 1,7 L apresentaram custo total unitário, respectivamente, $1.520,470$ e $660 \%$ superiores ao custo unitário dos subenxertos produzidos em tubetes de $290 \mathrm{~mL}$.

Embora o vigor de crescimento dos porta-enxertos, semeados diretamente em sacolas de 1,7 L, tenha sido superior, apontam-se algumas desvantagens, além do custo superior em relação ao sistema em tubetes de $290 \mathrm{~mL}$ : a necessidade de se aumentar o número de sementes por recipiente, no caso de espécies que apresentam altas taxas de embriões zigóticos e baixa poliembrionia; o subseqüente raleio de plântulas deve ser realizado com critério, a fim de se excluirem plantas zigóticas indesejáveis; e o fato de plantas produzidas em tubetes de $75 \mathrm{~mL}$ permitirem maior versatilidade de uso, seleção de plantas mais uniformes, antes do plantio, e possibilidade de transplante mais fácil. A rápida formação e o maior tamanho das plantas são destacados como características desejáveis para um subenxerto. Assim, a decisão sobre qual tipo de subenxerto adquirir dependerá não somente das condições do pomar a ser subenxertado, o que determinará o número e o tamanho dos subenxertos, como também de análise econômica das opções de recipientes e da disponibilidade de tempo para se proceder à subenxertia (Tersi, 2004).

\section{Conclusão}

Os porta-enxertos cítricos semeados diretamente em sacolas de 1,7 L atingem ponto ideal de subenxertia em menor tempo, de 100 a 150 dias após a semeadura, além de constituírem plantas maiores e com sistema radicular adequado, porém com custo de produção superior ao sistema de produção em tubetes de $290 \mathrm{~mL}$. 


\section{Agradecimentos}

À Fapesp pela concessão de bolsa; à empresa SaniCitrus Mudas Cítricas, pelo auxílio técnico na condução dos trabalhos de campo; ao Centro APTA Citros Sylvio Moreira, pelo fornecimento de parte do material vegetal utilizado nesta pesquisa; ao Dr. Jorgino Pompeu Junior e ao Dr. Eduardo Sanches Stuchi, pelas sugestões e comentários.

\section{Referências}

CARVALHO, S.A. de; GRAF, C.C.D.; VIOLANTE, A.R. Produção de material básico e propagação. In: MATTOS JUNIOR, D.M.; NEGRI, J.D. de; PIO, R.M.; POMPEU JUNIOR, J. Citros. Campinas: Instituto Agronômico: Fundag, 2005. p.281-316.

CASTLE, W.S. Citrus root systems: their structure, function, growth, and relationship to tree performance. Proceedings of the International Society of Citriculture, v.90, p.62-69, 1978.

CASTLE, W.S. Root system development in field- and container-grown young citrus trees. Proceedings of the Florida State for Horticultural Society, v.100, p.85-89, 1987.

CASTLE, W.S.; YOUTSEY, C.O. Root system characteristics of citrus nursery trees. Proceedings of the Florida State for Horticultural Society, v.90, p.39-44, 1977.

DOIJODE, S.D. Tropical and subtropical fruits - citrus fruits (Citrus spp.). In: DOIJODE, S.D. (Ed.). Seed storage of horticultural crops. New York: Haworth Press, 2001. p.23-40.

ESPOSTI, M.D.D.; SIQUEIRA, D.L. de; PEREIRA, P.R.G.; ALVAREZ VENEGAS, V.H.; SALOMÃO, L.C.C.; MACHADO FILHO, J.A. Assessment of nitrogenized nutrition of citrus rootstocks using chlorophyll concentrations in the leaf. Journal of Plant Nutrition, v.26, p.1287-1299, 2003.

FUNDECITRUS. Manual de morte súbita dos citros. Araraquara: Fundecitrus, 2006. 12p. Disponível em: <http://www.fundecitrus.com.br/ manuais/fdc_manual_msc_0406.pdf>. Acesso em: 15 out. 2006.

GIL, P.T.; FONTES, P.C.R.; CECON, P.R.; FERREIRA, F.A. Índice SPAD para o diagnóstico do estado de nitrogênio e para o prognóstico da produtividade da batata. Horticultura Brasileira, v.20, p.611-615, 2002.

GIRARDI, E.A.; MOURÃO FILHO, F.A.A. Crescimento inicial de laranjeira Valência sobre dois porta-enxertos em função da adubação nitrogenada no plantio. Revista Brasileira de Fruticultura, v.26, p.117119, 2004.

GIRARDI, E.A.; MOURÃO FILHO, F.A.A.; GRAF, C.C.D.; OLIC, F.B. Vegetative growth of citrus nursery trees related to the container volume. Fruits, v.59, p.101-105, 2005.

GIRARDI, E.A.; MOURÃO FILHO, F.A.A.; KLUGE, R.A. Effect of seed coat removal and controlled-release fertilizer application on plant emergence and vegetative growth of two citrus rootstocks. Fruits, v.62, p.13-19, 2007.
MORENO, P.; PIQUER, J.; NAVARRO, L.; CARBONELL, E.A.; PINA, J.A. Ensayos para evitar el decaimento causado por el virus de la tristeza de los cítricos (CTV) en arboles injertados sobre patron 'Naranjo Amargo'. Investigaciones Agrarias y Producción Vegetal, v.9, p.465-476, 1994.

MÜLLER, G.W.; NEGRI, J.D.; AGUILAR-VILDOSO, C.I.; MATTOS JÚNIOR, D.; POMPEU JÚNIOR, J.; TEÓFILO SOBRINHO, J.; CARVALHO, S.A.; GIROTTO, L.F.; MACHADO, M.A. Morte súbita dos citros: uma nova doença na citricultura brasileira. Laranja, v.23, p.371-386, 2002.

NAKAGAWA, J. Testes de vigor baseados na avaliação das plântulas. In: VIEIRA, R.D.; CARVALHO, N.M. (Ed.). Testes de vigor em sementes. Jaboticabal: Funep, 1994. p.49-85.

NAKAJIMA, Y.; XU, X.P.; HASEGAWA, K. Inarching of invigorating rootstock onto young pomelo trees grown under a plastic house. Journal of the Japanese Society for Horticultural Science, v.61, p.521-526, 1992.

NESMITH, D.S.; DUVAL, J.R. Transplant production and performance: the effect of container cell size. In: NATIONAL SYMPOSIUM ON STAND ESTABLISHMENT, 5., Columbus, 1997. Proceedings. Columbus: Ohio State University, 1997. p.2325.

PESTANA, M.; VARENNES, A.; ABADÍA, J.; FARIA, E.A. Differential tolerance to iron deficiency of citrus rootstocks grown in nutrient solution. Scientia Horticulturae, v.104, p.25-36, 2005.

POMPEU JUNIOR, J. Porta-enxertos. In: MATTOS JUNIOR, D.; NEGRI, J.D.; PIO, R.M.; POMPEU JUNIOR, P. (Ed.). Citros. Campinas: Instituto Agronômico de Campinas: Fundag, 2005. p.6394

POZZAN, M.; KANASHIRO, M. Custo de muda cítrica em viveiro telado. In: AGRIANUAL 2004: anuário da agricultura brasileira. São Paulo: Instituto FNP, 2004. p.250-253.

RADHAMANI, J.; MALIK, S.K.; CHANDEL, K.P.S. Seed coat characteristics in relation to the physiology of seed germination in Citrus and its allied genus. Seed Science and Technology, v.19, p.611-621, 1991.

REZENDE, L.P.; AMARAL, A.M. do; CARVALHO, S.A. de; SOUZA, M. Volume de substrato e superfosfato simples na formação do limoeiro 'Cravo' em vasos. I. Efeitos no crescimento vegetativo. Laranja, v.16, p.165-177, 1995.

SETIN, D.W. Avaliação de recipientes e tipo de enxertia na produção de mudas de citros com porta-enxertos duplos, visando prevenção contra estresse hídrico e morte súbita dos citros. Cordeirópolis: Instituto Agronômico de Campinas, 2005. 12p. Disponível em: <http:/ /www.vivecitrus.com.br/imagembank/Docs/DocBank/ $\%$ C $3 \% 81$ rea $\% 20$ Tecnica/Daves $\% 20 \mathrm{Setin} \% 20$ $\% 20$ Muda\%20turbinada.pdf $>$. Acesso em: 10 out. 2006.

SHAKED, A.; COHEN, A.; HAMOU, M.; HASDAI, D. Inarching of 'Swingle' citrumelo in Israel. HortScience, v.22, p.1258-1260, 1987.

SOARES FILHO, W.S.; MEDRADO, A.C.M.; CUNHA SOBRINHO, M.A.P.; PASSOS, O.S. Freqüência de híbridos em cruzamentos controlados de citros: cultivo de sementes versus cultivo in vitro de embriões. Pesquisa Agropecuária Brasileira, v.37, p.981-988, 2002. 
SPIEGEL-ROY, P.; GOLDSCHMIDT, E.E. Biology of horticultural crops: biology of citrus. Cambridge: Cambridge University Press, 1996. 230p.

STOFFELLA, P.J.; LI, Y.C.; PELOSI, R.R.; HAMNER, A.M. Citrus rootstock and carbon-dioxide enriched irrigation influence on seedling emergence, growth, and nutrient content. Journal of Plant Nutrition, v.18, p.1439-1448, 1995.
TERSI, F.E.A. Quanto custa a subenxertia em pomar cítrico. In: AGRIANUAL 2004: anuário da agricultura brasileira. São Paulo: Instituto FNP, 2004. p.254-256.

TERSI, F.E.A.; OJEDA, R.; GRAVENA, S. Curso teórico-prático de subenxertia: técnica preventiva para escape da doença morte súbita dos citros. Jaboticabal: Gravena ManEcol Edições, 2003. 52p.

Recebido em 1ำ de novembro de 2006 e aprovado em 4 de abril de 2007 